\title{
Detection and Quantification of African Swine Fever Virus in MA-104 Cells
}

Ayushi Rai ${ }^{1}, 2$, Sarah Pruitt ${ }^{1,2}$, Elizabeth Ramirez-Medina ${ }^{1,2}$, Elizabeth A. Vuono ${ }^{1,3}$, Ediane Silva1, 4 , Lauro Velazquez-Salinas ${ }^{1,4}$, Consuelo Carrillo ${ }^{5}$, Manuel V. Borca ${ }^{1, *}$ and Douglas P. Gladue ${ }^{1, *}$

${ }^{1}$ Agricultural Research Service Plum Island Animal Disease Center, Greenport, NY, USA; ${ }^{2}$ Oak Ridge Institute for Science and Education (ORISE), Oak Ridge, TN, USA; ${ }^{3}$ Department of Pathobiology and Population Medicine, Mississippi State University, Starkville, USA; ${ }^{4}$ Department of Anatomy and Physiology, Kansas State University, Manhattan, USA; ${ }^{5}$ APHIS, USDA, Plum Island Animal Disease Center, Greenport, New York, USA

*For correspondence: Manuel.Borca@usda.gov; Douglas.Gladue@usda.gov

[Abstract] Detection of live African swine fever virus (ASFV) has historically relied on the use of primary swine macrophages (PSM). PSM do not replicate and have to be isolated fresh from donor swine. We previously identified that a MA-104 cells (ATCC \#CRL-2378.1), a commercially available cell line isolated from African green monkey (Cercopithecus aethiops) kidney epithelial cells, supports the detection of ASFV from field samples with a sensitivity comparable to that of primary swine macrophages. Collection of swine blood or lungs is time costing, which is often not readily available in most veterinary diagnostic laboratories. MA-104 cells could thus be used as substitute for primary swine macrophages to save significant lead time by avoiding the production of primary swine macrophages.

Keywords: ASFV, ASF, African swine fever cell line, Diagnostics, MA-104

[Background] African swine fever virus (ASFV), a member of Asfarviridae family, causes a highly contagious and lethal hemorrhagic fever, namely African swine fever (ASF) in wild boars and domesticated pigs. The mature virus particle (virion) has $175-215 \mathrm{~nm}$ diameter, with a lipid bilayer enclosing an icosahedral capsid and a 180-190 kilobase pairs long double-stranded DNA genome. The virus causes a wide-spectrum of symptoms including highly lethal to sub-clinical, depending on host characteristics and the virus strain (Tulman et al., 2009). Preliminary diagnosis of ASFV in clinical samples (typically whole blood) is performed using real-time polymerase chain reaction (rt-PCR), which detects pieces of viral genome but active infection, the latter is confirmed via virus isolation and further downstream analyses, such as whole genome sequencing. Before the publication of our recent work identifying MA-104 cells as a substrate for ASFV detection (Rai et al., 2020), infectious virus detection could only be performed in primary macrophage cultures prepared from fresh pig blood. This protocol uses commercially available African green monkey cell line MA-104 (Whitaker and Hayward, 1985) as a substitute for detection and quantification of infectious ASFV either by hemadsorption (HA) or by staining with specific antibody for ASFV. 


\section{Materials and Reagents}

1. $10 \mu \mathrm{l}, 20 \mu \mathrm{l}, 200 \mu \mathrm{l}, 1,000 \mu \mathrm{l}$ pipette tips (Thermo Fisher Scientific, catalog numbers: 2140-05, 72830-440, 72830-044, 72830-042)

2. $1 \mathrm{ml}, 5 \mathrm{ml}, 10 \mathrm{ml}, 25 \mathrm{ml}, 50 \mathrm{ml}$ sterile serological pipettes (Thermo Fisher Scientific, catalog numbers: $14672-918,14672-920,4101,14672-900,53384-451)$

3. 6-well tissue culture dishes (Corning, Falcon ${ }^{\circledR}$, catalog number: 353046 )

4. 96-well tissue culture flat bottom plate with sterile lid (Costar ${ }^{\mathrm{TM}}$, catalog number: 29442-056)

5. Deep well 96-well plates, sterile (Life Technologies, catalog number: 11388-566)

6. 15 and $50 \mathrm{ml}$ Conical tubes (Corning, Falcon ${ }^{\circledR}$, catalog numbers: 353110 and 352098 )

7. Polypropylene microcentrifuge tubes (Life Technologies|AB/Invitrogen, catalog number: AM12400)

8. $2 \mathrm{ml} \mathrm{screw}$ cap tubes (Sarstedt, catalog number: 72.694.006)

9. T-75 flask (Corning, catalog number: $3276 \mathrm{CS}$ )

10. T-150 flask (Corning, catalog number: 430825)

11. WYPALL Absorbent toweling (Kimberly-Clark ${ }^{\circledR}$ Professional, catalog number: KIM41200)

12. Reservoirs (Costar Reagent Reservoir, Corning ${ }^{\circledR}$, catalog number: 29442-474)

13. Freezing vial (Corning, catalog number: 431386)

14. MA-104 Clone 1 cells were obtained by American Tissue Culture Collection (ATCC, catalog number: CRL-2378.1)

15. Dulbecco's Phosphate Buffered Saline (DPBS) $1 \times$ no calcium, no magnesium, pH 7.0-7.3 (Thermo Fisher Scientific, Gibco ${ }^{\mathrm{TM}}$, catalog number: 14190-250)

16. Gamma Irradiated Fetal bovine serum (GE Healthcare, Hyclone ${ }^{\mathrm{TM}}$, catalog number: SH3007103IREA-HYL)

17. $1 \times$ antibiotic-Antimycotic (Life Technologies|AB/Invitrogen, catalog number: 15240062)

18. $0.25 \%$ Trypsin $0.53 \mathrm{mM}$ EDTA (Life Technologies|AB/Invitrogen, catalog number: 12604-013)

19. DMEM (Fisher Scientific, catalog number: 11965-118)

20. Recovery Freezing Medium (Thermo Fisher, catalog number: 12648-010)

21. Acetone (Fisher Scientific, catalog number: A18-4)

22. Methanol (Fisher Scientific, catalog number: A412P4)

23. Isopropanol (Fisher Scientific, catalog number: A415-4)

24. Ethanol (Sigma-Aldrich, catalog number: E7023)

25. Horse serum (Vector Laboratories, catalog number: S-2000)

26. ASFV p30 monoclonal antibody produced by APHIS, USDA (Wu et al., 2020)

27. Vectastain ${ }^{\circledR}$ ABC kit, Peroxidase Mouse IgG (Vector Laboratories, catalog number: PK4002)

28. Vector ${ }^{\circledR}$ VIP, Peroxidase substrate kit SK-4600 (Vector Laboratories, catalog number: ZF0517)

29. Bovine Albumin Fraction V Low endotoxin, BSA (MP Biomedicals, catalog number: 810681)

30. ASFV field strain: For example an ASFV-Georgia field strain (ASFV-G)

31. MA-104 media (see Recipes) 
32. Blocking buffer (see Recipes)

33. Fixing Solution (see Recipes)

34. $25 \%$ v/v suspension of swine red blood cells (see Recipes)

35. $0.1 \%$ BSA (see Recipes)

36. $70 \%$ Ethanol (see Recipes)

\section{Equipment}

1. $2 \mathrm{~L}$ beaker

2. Mr. Frosty Freezing Container (Nalgene, catalog number: 5100-0001)

3. Class II biological safety cabinet $\left(\mathrm{LABCONCO}^{\circledR}, \mathrm{NSF}^{\circledR}\right.$, model: D045939)

4. Humidified $37 \pm 2{ }^{\circ} \mathrm{C}, 5 \pm 1 \% \mathrm{CO}_{2}$ incubator (Panasonic, catalog number: KM-CC17RU1A)

5. $-70{ }^{\circ} \mathrm{C}$ freezer (Panasonic MDF-U76VA-PA, catalog number: 17117N0425)

6. $-20^{\circ} \mathrm{C}$ freezer (Kenmore, model: 2539261110 )

7. Refrigerator, $4{ }^{\circ} \mathrm{C}$, with an acceptable range of $2{ }^{\circ} \mathrm{C}$ to $8{ }^{\circ} \mathrm{C}$ (Sanyo Medicool, model: MPR-513)

8. Liquid nitrogen Freezer $<-120^{\circ} \mathrm{C}$ storage temp.

9. Water bath, $37^{\circ} \mathrm{C}$ (Lab-line Aquabath ${ }^{\mathrm{TM}}$, model: 18052AQ)

10. Pipet aid (Drummond Scientific, catalog number: 4-000-101)

11. Micropipettors: Single channel, 1-10 $\mu \mathrm{l}, 2-20 \mu \mathrm{l}, 50-200 \mu \mathrm{l}, 100-1,000 \mu \mathrm{l}$ (Eppendorf catalog numbers: Q11390H, K12770H, Q24196H, L18745H)

12. Micropipettors: Multi-channel, 0.5-10 $\mu \mathrm{l}, 5-50 \mu \mathrm{l}, 50-300 \mu \mathrm{l}$ (Lab System, catalog numbers: N87539, D23745, E21512)

13. Multi-channel for larger volumes (Rainin ${ }^{\text {TM }}$ Pipet-Life XLS, L-1200, 100-1,200 $\mu$, catalog number: 17014497)

14. Inverted Microscope (Carl-Zeiss, model: Axio Observer 3)

15. Bright line Hematocytometer (Sigma, catalog number: Z359629)

16. Tabletop Centrifuge (Eppendorf, model: 5417R)

17. Sorvall ${ }^{\circledR}$ LYNX 6000 (Thermo Fisher Scientific, catalog number: 75006590)

18. Vortex mixer (Daigger vortex Genie2 ${ }^{\mathrm{TM}}$, catalog number: $\mathrm{G} 22220$ )

19. Plate shaker (Gene Mate, BioExpress Rocker Variable, catalog number: R-3200-1)

\section{Procedure}

A. Thaw frozen vial of MA-104 cells received from ATCC on dry ice or frozen in liquid nitrogen

1. Remove the frozen vial of MA-104 cells either from dry ice or liquid nitrogen storage.

2. Thaw MA-104 cells in a $37^{\circ} \mathrm{C}$ water bath.

3. Keep the lid of the MA-104 cell frozen vial above the surface of the water to lessen the chances of contamination. 
4. When the MA-104 cells are almost thawed (only a small piece of ice) move the vial to the tissue culture hood.

5. Wipe the surface of the vial with $70 \%$ ethanol and remove the top.

6. Carefully remove the MA-104 cell suspension using a sterile Pasteur pipette.

7. Gently add MA-104 cells in T75 flask containing $15 \mathrm{ml}$ of pre-warmed MA-104 media at $37^{\circ} \mathrm{C}$

8. Place the MA-104 cells in $\mathrm{T} 75$ flasks in a $5 \% \mathrm{CO}_{2}$ incubator.

9. After $24 \mathrm{~h}$ discard the old media.

10. Add $15 \mathrm{ml}$ of MA-104 media in T-75 flask and place the flask in a $5 \% \mathrm{CO}_{2}$ incubator.

B. MA-104 cell sub culturing when confluent (Figure 1) at ratios 1:3 to 1:10

1. Remove and discard culture media.

2. Rinse the MA-104 cell monolayer with $10 \mathrm{ml} 1 \times$ DPBS.

3. To remove traces of serum that contains trypsin inhibitor, briefly rinse the cell monolayer with a $0.25 \%(w / v)$ Trypsin-0.53 mM EDTA solution.

4. Add $3.0 \mathrm{ml}$ Trypsin-EDTA to the flask and keep the flask in $5 \% \mathrm{CO}_{2}$ incubator and observe every 2 min under an inverted microscope until cell monolayeris completely dispersed (typically takes 5-15 min).

5. Add $8.0 \mathrm{ml}$ MA-104 media and break cells by gently pipetting up and down

6. Add approximately $1 \mathrm{ml}$ aliquot of the cell suspension to new T-150 flask

7. Incubate culture in an $5 \% \mathrm{CO}_{2}$ incubator at $37^{\circ} \mathrm{C}$

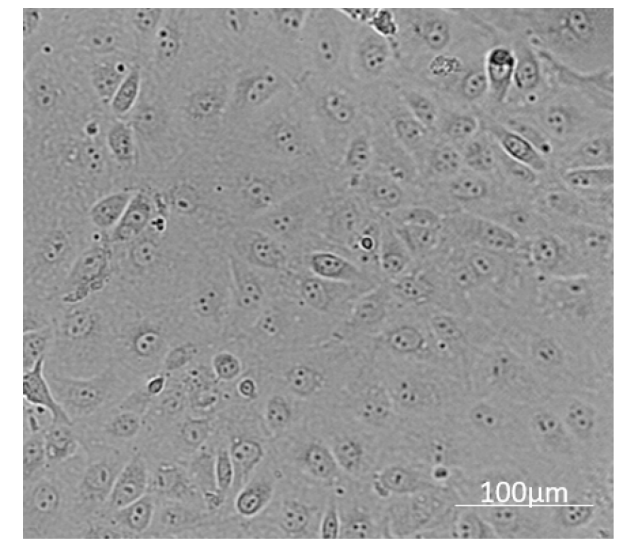

Figure 1. MA-104 cells at $100 \%$ confluency and ready to be subcultured into new flasks

Subculture and plating ratios used to prepare MA-104 cells:

To achieve $80 \%$ confluency of MA-104 cells 2 days after splitting a ratio of $1: 3$ is used.

To achieve $80 \%$ confluency of MA-104 cells $4-5$ days after splitting a ratio of 1:10 is used.

To culture MA-104 cells in 6-well culture dishes, seed at $1 \times 10^{6}$ cells/well.

To culture MA-104 cells in 96-well culture dishes, seed at $1 \times 10^{4}$ cells/well.

C. Procedure to freeze MA-104 cells 
1. Before freezing MA-104 cells check for bacterial, yeast, or fungal contamination under inverted microscope.

2. Freeze only healthy cells in the log phase of growth (between $70-90 \%$ confluency; Figure 2 ).



Figure 2. MA-104 cells shown growing in active log phase ready to be prepared for frozen stocks

3. Split MA-104 cells: Discard old growth media. Wash cell monolayer with $10 \mathrm{ml} 1 \times$ DPBS then discard $1 \times$ DPBS. Rinse cells with trypsin/EDTA and discard it and then add $3 \mathrm{ml}$ of trypsin/EDTA. Once cells start detaching, give the flask a gentle pat and re-suspend the cells with $8 \mathrm{ml}$ of growth media. Disperse cells by gently pipetting up and down to break clumps and get a homogeneous suspension.

4. Count the cells using hemacytometer under inverted microscope.

5. Number of cells used to freeze should be in the range of $5 \times 10^{6}-1 \times 10^{7}$ cells/vial. Calculate the volume of freezing media needed for a final cell concentration to be in this range.

6. Transfer cell suspension to sterile centrifuge tubes, balance the centrifuge, and centrifuge at $201 \times g(1,000 \mathrm{rpm})$ for $5 \mathrm{~min}$.

7. Carefully remove as much supernatant as possible without disturbing the pellet

8. Quickly re-suspend pellet by adding the calculated amount of recovery freezing medium (Thermo Fisher, catalog number: 12648-010) in a $2 \mathrm{ml}$ screw cap tube, and label the tube.

9. Place the vials in Mr. Frosty Freezing Container, which allows the cells to cool down slowly.

10. Close the freezing container and place at $-70{ }^{\circ} \mathrm{C}$ for at least overnight.

11. Next day, transfer the vials of frozen MA-104 to liquid nitrogen

D. ASFV titration in MA-104 cells detection by Hemadsorption (HA)

1. For titration in 96-well culture plates use $1 \times 10^{4}$ cells/well prepared in MA-104 media; recommended volume of cell suspension/well is $100 \mu \mathrm{l}$.

2. Prepare ten-fold serial dilutions of each ASFV sample (swine blood) using MA-104 media.

3. Add $50 \mu$ l of each dilution of ASFV samples in order from $10^{-7}$ to $10^{-1}$ to the plate wells containing $100 \mu$ of MA-104 cells. 
4. Incubate cells at $37{ }^{\circ} \mathrm{C}$ with $5 \% \mathrm{CO}_{2}$.

5. $24 \mathrm{~h}$ post infection (hpi), add $1 \mu \mathrm{l}$ of $25 \% \mathrm{v} / \mathrm{v}$ suspension of swine red blood cells to each well of MA-104 cells in the plate.

6. Incubate at $37^{\circ} \mathrm{C}$ with $5 \% \mathrm{CO}_{2}$ for seven days of incubation.

7. Observe the plates under the inverted microscope for Hemadsorption to confirm the infection.

8. Calculate virus titer using the Reed and Muench method (Reed and Muench, 1938) by Hemadsorping dose (HAD) and express it as $\log _{10} \mathrm{HAD} 50 / \mathrm{ml}$.

E. Detection of ASFV infection in MA-104 by HA

1. For HA, plate $2 \mathrm{ml}$ of MA-104 cell suspension prepared in MA-104 media at a density of $1 \times 10^{6}$ cells/well in 6-well tissue culture dishes.

2. Add ASFV field sample to three wells of the 6-well plate with $1 \mu \mathrm{l}, 10 \mu \mathrm{l}$ and $100 \mu \mathrm{l}$.

3. $1 \mathrm{hpi}$, add $100 \mu \mathrm{l}$ of $25 \% \mathrm{v} / \mathrm{v}$ suspension of swine red blood cells were to each well.

4. $24 \mathrm{hpi}$, observe ASFV-infected cells for rosette formation in MA-104 cells (Figure 3). Depending on quantity and quality of the ASF sample, rosettes may take longer to form, if no rosettes are observed at $24 \mathrm{hpi}$, check daily for 7 days.



Figure 3. MA-104 cells infected with ASFV-G and incubated with red blood cells showing clear HA

F. Immunoperoxidase (IPA) staining for ASFV in MA-104 cells

\section{*Perform on Biosafety cabinet*}

1. Plate $2 \mathrm{ml}$ of MA-104 cell suspension prepared in MA-104 media at a density of $1 \times 10^{6}$ cells/well in 6-well tissue culture dishes.

2. Add ASFV field sample to three wells of the 6 -well plate with $1 \mu \mathrm{l}, 10 \mu \mathrm{l}$ and $100 \mu \mathrm{l}$.

3. Incubate the plates at $37^{\circ} \mathrm{C}$ in an incubator for $72 \mathrm{~h}$.

4. Take the plates out of the incubator.

5. Discard media by inverting plate and dumping media into $2 L$ beaker and then the rest of the media soaked by inverting plates onto thick paper towels kept in tray container

6. Fix the cells using $2 \mathrm{ml}$ of fixing solution (1:1 solution of acetone and methanol) in each well. 
7. Incubate the plate(s) at room temperature for $15-20 \mathrm{~min}$.

8. Prepare solutions:

- Blocking solution: DMEM $+2 \%$ normal horse serum kept at $4{ }^{\circ} \mathrm{C}$

- Antibody solution: DMEM $+2 \%$ normal horse serum + ASFV p30 monoclonal antibody (1:200 dilution) kept $4{ }^{\circ} \mathrm{C}$

- Anti-mouse IgG solution: DMEM + $2 \%$ normal horse serum $+0.25 \%$ anti-mouse IgG (Vectastain ABC kit, Peroxidase Mouse IgG) kept at $4{ }^{\circ} \mathrm{C}$

- 1× DPBS + BSA + A + B solution: 1× DPBS + 0.1\% BSA + 0.6\% A + 0.6\% B ('A' and ' $B$ ' are components of Vectastain $A B C$ kit) kept at $4{ }^{\circ} \mathrm{C}$

- Peroxidase substrate solution: $1 \times$ DPBS (from lab container) + Vector $^{\circledR}$ VIP reagents kept at $4{ }^{\circ} \mathrm{C}$ (Use 3 drops from each of the four bottles per $5 \mathrm{ml}$ solution)

\section{*Perform on benchtop*}

9. Discard fixing solution in a $2 \mathrm{~L}$ beaker, invert the plate over thick paper towel to remove the leftover fixing solution and air-dry plates for $10 \mathrm{~min}$.

10. Add $2 \mathrm{ml} /$ well Blocking solution. Gently tap or shake the plate to ensure the entire surface of each well is covered by the solution.

11. Incubate the plate(s) at $37^{\circ} \mathrm{C}$ for $30 \mathrm{~min}$.

12. Discard of Blocking solution in a $2 \mathrm{~L}$ beaker and invert the plates over thick paper towel to remove the leftover Blocking solution.

13. Add $2 \mathrm{ml} /$ well Antibody solution.

14. Incubate the plate(s) at $37^{\circ} \mathrm{C}$ for $30 \mathrm{~min}$.

15. Discard of Antibody solution in a $2 \mathrm{~L}$ beaker and rinse 2 times with 1 XDPBS by using squeeze bottle.

16. Add $2 \mathrm{ml} /$ well of Anti-mouse IgG solution.

17. Incubate the plate(s) at $37^{\circ} \mathrm{C}$ for $30 \mathrm{~min}$.

18. During the 30 min incubation, prepare $1 \times$ DPBS $+B S A+A+B$ solution. Add $0.1 \% B S A$ $\mathrm{w} / \mathrm{v}$ in $1 \times$ DPBS and mix thoroughly, next add $0.6 \% \mathrm{v} / \mathrm{v}$ solution $A$ and solution $B$ from Vectastain ABC kit stock. Keep the freshly prepared 1 $1 \times$ DPBS $+B S A+A+B$ solution at room temperature.

19. Discard Anti-mouse IgG solution in $2 \mathrm{~L}$ beaker and rinse 2 times with $1 \times$ DPBS using squeeze bottle.

20. Add $2 \mathrm{ml} /$ well $1 \times$ DPBS + BSA + A + B solution.

21. Incubate the plate(s) at $37^{\circ} \mathrm{C}$ for $30 \mathrm{~min}$.

22. Discard $1 \times$ DPBS $+B S A+A+B$ solution in a $2 L$ beaker and wash 2 times with $1 \times$ DPBS by using squeeze bottle.

23. Add $2 \mathrm{ml} /$ well Peroxidase substrate solution.

24. Incubate the plates at room temperature for $10 \mathrm{~min}$.

25. Discard Peroxidase substrate solution in a $2 L$ beaker and rinse the plates with tap water. 
26. Air-dry the plate for $10 \mathrm{~min}$.

27. Calculate the titer using Reed and Muench method (Reed and Muench, 1938). Figure 4 shows positive ASFV staining.

Note: Take extra caution in performing the washes, because each wash step requires a different solution and cross contamination between solutions could potentially lead to failed experiment and erroneous readings.

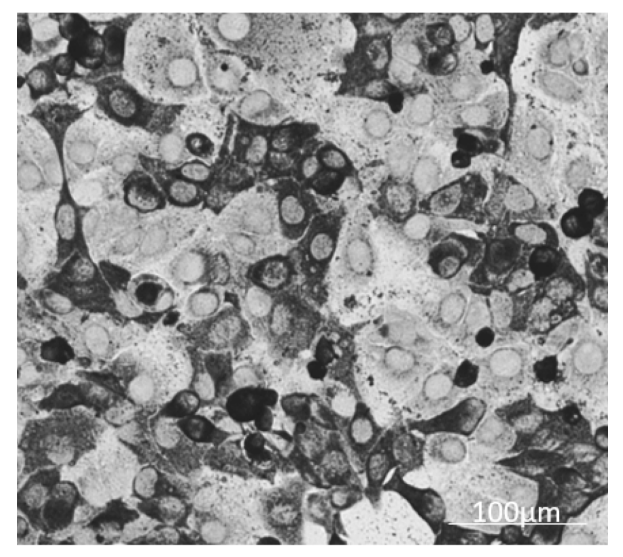

Figure 4. Fixed MA-104 cells infected with ASFV-G that were IPA stained for ASFV using monoclonal antibody against a structural protein p30, the MA-104 cells show clear staining for ASFV

\section{Data analysis}

Requirement of virus culture in primary swine macrophages is a technically challenging process and was historically done for detecting and quantifying infectious ASFV. We previously identified MA104 cells as a commercially available cell line which supports robust ASFV growth, allowing the detection of infectious ASFV from clinical and field samples (Rai et al., 2020). MA-104 cells have a doubling time of $72 \mathrm{~h}$ and, importantly, there are no requirements of any special media for growing these cells nor conducting virus culture in these cells. MA-104 cells can be easily frozen in large quantities, allowing timely expansion of the cells in quantities required in a disease outbreak when a large number of samples needs to be processed to confirm whether samples contain just ASFV DNA or infectious ASFV virus. Therefore, MA-104 cells can aid in the rapid diagnosis of ASFV by bypassing the need for producing primary cell cultures of swine macrophages (which require fresh swine blood, something not readily available at common veterinary diagnostic laboratories). Infectious ASFV in MA-104 cells can be easily detected by either HA or IIPA staining using antiASFV specific antibodies. IPA staining can further allow the detection of ASFV field isolates that has mutations in CD2, and would be unable to form HA. IPA staining would be used in instances where PCR was positive but no HA was observed to determine the presence of live infectious virus in a sample (Borca et al., 2018). The clear staining of ASFV-infected cells by IPA is advantageous over using swine macrophages as a substrate, because swine macrophages have intrinsic peroxidase 
activity leading to a high staining background in uninfected cells, leading to false positive reactions (Rai et al., 2020).

\section{$\underline{\text { Notes }}$}

1. When thawing MA-104 cells never leave cell vial unattended, because at $37^{\circ} \mathrm{C}$, cell thawing completes within 1-2 min, and long exposure at $37^{\circ} \mathrm{C}$ causes cryoprotectant toxicity. Remove the vial from the water bath when still a few ice crystals remain.

2. Cells are particularly sensitive immediately post thaw. They should be seeded into pre-warmed medium.

3. Low seeding densities should be avoided for starting the cells taken out of liquid nitrogen storage or vendor supplied vial.

4. While waiting for the cells to detach, do not agitate the cells by hitting or shaking the flask to avoid cell clumping. Place cells that are difficult to detach for extended time at $37^{\circ} \mathrm{C}$ to facilitate dispersal.

5. Don't store the cells at $-70^{\circ} \mathrm{C}$ for more than 2 days. It will decrease cell viability.

6. When freezing the cells, do not leave them in Recovery freezing medium at room temp for long time because cryoprotectants in the media are toxic to cells.

7. This protocol shall be conducted in an animal Biosafety level 3 laboratory, because ASFV is a select agent, which can only be handled in a designated animal Biosafety level 3 laboratory.

8. Exterior of the container need to be surface decontaminated by wiping with $10 \%$ bleach soaked towel.

9. To transfer virus containing vials, plates or storage boxes between different work areas and the storage, always use an air-sealed secondary container.

10. Open the secondary container only in a Biosafety cabinet. Before taking out of the Biosafety cabinet surface contaminate both the vial/plate/box and the secondary container.

11. Contain all the solid and liquid waste in approved Biohazard container. Dispose of all material used in the experiment after autoclaving at appropriate cycle.

\section{$\underline{\text { Recipes }}$}

1. MA-104 Media

500 ml DMEM

$50 \mathrm{ml} \mathrm{FBS}$

$5 \mathrm{ml}$ Antibiotic-Antimycotic

2. Blocking Buffer

$500 \mathrm{ml}$ DMEM

$10 \mathrm{ml}(2 \%)$ Horse serum

3. Fixing Solution (1:1 solution of acetone and methanol) 
$50 \mathrm{ml}$ Acetone

$50 \mathrm{ml}$ Methanol

4. $0.1 \% \mathrm{BSA}$

Add $0.5 \mathrm{~g} \mathrm{BSA}\left(4^{\circ} \mathrm{C}\right)$ to $500 \mathrm{ml} 1 \times$ DPBS bottle

5. $25 \% \mathrm{v} / \mathrm{v}$ suspension of swine red blood cells

Add $9 \mathrm{ml}$ of red cells pellet and $27 \mathrm{ml}$ of $1 \times$ DPBS to make $25 \%$ blood in $1 \times$ DPBS

Store at $4{ }^{\circ} \mathrm{C}$ label $\%$ of red blood cells in pbs and date

6. $70 \%$ Ethanol

$70 \mathrm{ml} 100 \%$ Ethanol

$30 \mathrm{ml} \mathrm{dH_{2 } \mathrm { O }}$

\section{Acknowledgments}

The identification of Ma-104 cells funded through an interagency agreement with the Science and Technology Directorate of the U.S. Department of Homeland Security under Award Number: 70RSAT18KPM0000138.

This research was supported in part by an appointment to the Plum Island Animal Disease Center (PIADC) Research Participation Program administered by the Oak Ridge Institute for Science and Education (ORISE) through an interagency agreement between the U.S. Department of Energy (DOE) and the U.S. Department of Agriculture (USDA). ORISE is managed by ORAU under DOE contract number DE-SC0014664.

\section{Competing interests}

The authors Ayushi Rai, Manuel Borca and Douglas Gladue have filed a patent for using MA-104 cells as a substrate for detection of ASFV.

\section{$\underline{\text { References }}$}

1. Borca, M. V., Holinka, L. G., Berggren, K. A. and Gladue, D. P. (2018). CRISPR-Cas9, a tool to efficiently increase the development of recombinant African swine fever viruses. Sci Rep 8: 3154.

2. Rai, A., Pruitt, S., Ramirez-Medina, E., Vuono, E. A., Silva, E., Velazquez-Salinas, L., Carrillo, C., Borca, M. V. and Gladue, D. P. (2020). Identification of a Continuously Stable and Commercially Available Cell Line for the Identification of Infectious African Swine Fever Virus in Clinical Samples. Viruses 12(8). doi:10.3390/v12080820.

3. Reed, L. J. and Muench, H. (1938). A simple method of estimating fifty percent endpoints. The American J Hygiene 27(3): 493-497.

4. Tulman, E. R., Delhon, G. A., Ku, B. K. and Rock, D. L. (2009). African Swine Fever Virus. In: Lesser Known Large dsDNA Viruses. Springer-Verlag Berlin Heidelberg Vol. 328 pp. 43-87. 
5. Whitaker, A. M. and Hayward, C. J. (1985). The characterization of three monkey kidney cell lines. Dev Biol Stand 60: 125-131.

6. Wu, P., Lowe, A. D., Rodriguez, Y. Y., Murgia, M. V., Dodd, K. A., Rowland, R. R. and Jia, W. (2020). Antigenic regions of African swine fever virus phosphoprotein P30. Transbound Emerg Dis doi:10.1111/tbed.13533. 